\title{
Evaluation of China's High-quality Development from the Perspective of Ecological Civilization
}

\begin{abstract}
Hongwu Zhang ${ }^{*}$ and Rong Fu
Business School of Guangzhou College of Technology and Business, China

*Corresponding author. Email: 1150367230@qq.com

ABSTRACT

High-quality development is a very broad concept, and the development of ecological civilization is the key of highquality development. The development of ecological civilization can be decomposed into green development, circular development and low-carbon development. Based on entropy method, a comprehensive evaluation of the development of China's ecological civilization from 2000 to 2017 shows that overall, the development of ecological civilization has made some progress: the development trend is good, but the development is not balanced: the green development is faster than low-carbon development and the circular development. During the process of development, it has gone through several periods such as a period of decline and lingering, a period of uneven development and a period of steady rise. In the future, we should attach importance to the balanced development of ecological civilization, continuing to strengthen the quality of the environment, the efficient use of resources and the transformation of energy, so as to promote the construction of ecological civilization to meet the requirements of high-quality development in China.
\end{abstract}

Keywords: High-quality development, Ecological civilization, Entropy method, Green development, Circular development, Low-carbon development.

\section{INTRODUCTION}

In the present, China's economy has shifted from a stage of rapid growth to a stage of high-quality development which refers to meet the people's evergrowing needs for a better life, and embodies the concept of innovative, coordinated, green, open and Shared development. Bedsides, it reflects that involves less input of production factors and lower environmental costs, meanwhile allocates the resources more efficiency and generates higher economic and social benefits. Eventually, an important sign of high-quality development is to continuously improve the input and output efficiency of labor, capital, land, resources, environment and other elements as well as more emphasis on the overall development and progress of the five aspects of economy, politics, society, culture and ecology. Therefore, high-quality development understood from a broad perspective is not only limited to the economic category, but also considered social, political, cultural, ecological and other factors. Furthermore, it improves the quality of products, services, facilities and the environment, also involves the cooperation of various measures in terms of philosophy, culture, system, and policies.

Accordingly, high-quality economic development is a very broad concept. This study attempts to evaluate the level of high-quality development based on the perspective of ecological civilization in China.

\section{CONSTRUCTION OF CHINA'S HIGH- QUALITY DEVELOPMENT EVALUATION INDEX SYSTEM FROM THE PERSPECTIVE OF ECOLOGICAL CIVILIZATION}

\subsection{Existing Research and Review}

The prerequisite for measuring high-quality development is to construct an evaluation index system for high-quality development. Many scholars have discussed the construction of the index system. For instance, According to the connotation of high-quality development, Zhu Weidong et al. (2019), divided the indicator system of high-quality development into ten dimensions, such as innovation, coordination, green, 
open, sharing, efficiency, quality, structure, safety and sustainability, etc., measured 137 secondary indicators [1]. Zhu Qigui et al.(2018) has more than 60 secondary indicators from 6 dimensions including power change, industrial upgrading, structural optimization, quality change, efficiency change, and People's livelihood development [2]. Song Mingshun et al. (2015) selected 8 secondary indicators for evaluation in the three dimensions of competition quality, people's livelihood quality, and ecological quality [3]. Wei Min and Li Shuhao (2018) selected 30 secondary indicators for evaluation from 5 dimensions including power mechanism transformation, economic structure optimization, openness, stability and sharing, ecological environment harmony, and people's happiness in life [4]. Lu Jitong(2017) constructed an evaluation system of 52 secondary indicators from the three dimensions of micro, meso and macro [5]. Xu Yongbing et al. (2019) evaluated 24 secondary indicators from 6 dimensions including innovation drive, structural optimization, economic stability, economic vitality, improvement of peoples' livelihood, and Eco-friendliness [6]. Han Junhui et al. (2019) selected 23 secondary indicators from the four links of production, distribution, exchange and consumption to evaluate [7]. Liu Gan, Zheng Siyu (2018) selected 5 secondary indicators from both dynamic and static perspectives for evaluation [8].
In addition, there are also studies on the high-quality development of specific industries in China, such as Song Xiaona, Zhang Feng's research on industrial development [9], Liang Tao (2019)[10] Zhang Wenhui, Qiao Baohua (2018)[11] research on manufacturing industry, etc

In the process of constructing a high-quality development indicator system, the aforementioned scholars have different observation angles and different understandings of the connotation with different indicators selected. From the existing literature, most of the studies are trying to depict the overall picture of high-quality development, while the evaluation from a certain aspect of high-quality development is still relatively rare, which cannot but be regarded as a deficiency. Because the evaluation of economic development quality is a very complex systematic project, in order to systematically carry out a comprehensive evaluation in an article, it may involve a lot of indicators which will affect the depth of the evaluation. Based on this, this paper intends to make a preliminary investigation on the development level of China's ecological civilization from the perspective of high-quality development, in order to have a clear understanding of the current situation of ecological civilization development in high-quality aspect.

Table 1. China's high-quality development evaluation index system based on the perspective of ecological civilization

\begin{tabular}{|c|c|c|c|}
\hline \multirow[b]{2}{*}{$\begin{array}{l}\text { First-level } \\
\text { index }\end{array}$} & \multicolumn{3}{|c|}{ Second-level index } \\
\hline & $\begin{array}{l}\text { Index } \\
\text { code }\end{array}$ & Index name & Unit of measurement \\
\hline \multirow{6}{*}{$\begin{array}{l}\text { Circular } \\
\text { development }\end{array}$} & $\mathrm{X} 1$ & Total energy consumption & 100 million tons of standard coal \\
\hline & $\mathrm{X} 2$ & Total water consumption & 100 million cubic meters \\
\hline & $\mathrm{X} 3$ & Energy consumption per unit of GDP & Ton standard coal/10,000 yuan \\
\hline & $\mathrm{t} 4$ & Water consumption per unit of GDP & $\mathrm{m} 3 / 10,000$ yuan \\
\hline & $\mathrm{X} 5$ & Daily urban sewage treatment capacity & 100 million cubic meters \\
\hline & $\mathrm{X} 6$ & Comprehensive utilization rate of industrial solid & $\%$ \\
\hline \multirow{10}{*}{$\begin{array}{l}\text { Green } \\
\text { development }\end{array}$} & $\mathrm{X} 7$ & Total sulfur dioxide emissions & 10,000 tons \\
\hline & $\mathrm{X} 8$ & Total smoke (dust) emissions & 10,000 tons \\
\hline & $\mathrm{X} 9$ & Total wastewater discharge & 100 million tons \\
\hline & $\mathrm{X} 10$ & Chemical oxygen demand emissions & 10,000 tons \\
\hline & $\mathrm{X} 11$ & Sulfur dioxide emissions per unit of GDP & 10,000 tons $/ 10,000$ yuan \\
\hline & $\mathrm{t}$ 12 & Smoke (dust) emission per unit of GDP & 10,000 tons $/ 10,000$ yuan \\
\hline & $\mathrm{X} 13$ & Total wastewater discharge per unit of GDP & tons/10,000 yuan \\
\hline & $\mathrm{X} 14$ & $\begin{array}{l}\text { Chemical oxygen demand emissions per unit of } \\
\text { GDP }\end{array}$ & 10,000 tons $/ 10,000$ yuan \\
\hline & $\mathrm{X} 15$ & Urban green area & Ten thousand hectares \\
\hline & $\mathrm{X} 16$ & Urban park green area per capita & M2 /person \\
\hline \multirow{5}{*}{$\begin{array}{l}\text { Low-carbon } \\
\text { development }\end{array}$} & $\mathrm{X} 17$ & Total carbon dioxide emissions & 100 million tons \\
\hline & $\mathrm{X} 18$ & Carbon dioxide emissions per unit of GDP & ton/10,000 yuan \\
\hline & $\mathrm{t}$ X19 & Carbon dioxide emissions per capita & ton/person \\
\hline & $\mathrm{X} 20$ & Non-fossil energy utilization & 10,000 tons of standard coal \\
\hline & $\mathrm{X} 21$ & Non-fossil energy utilization ratio & $\%$ \\
\hline
\end{tabular}

Source: Compiled by the author 


\subsection{Construction of Evaluation Index System}

Constructing a high-quality development index system requires the connotation of high-quality development as a reference and basis. The author believes that the development of ecological civilization is an important part of high-quality development from the perspective of ecological civilization which have to meets the requirements of circular development, green development and low-carbon development.

\subsubsection{Circular Development}

Circular development is a kind of model that takes the high efficiency and recycling of resources as the core, low consumption, low emissions, and high efficiency as its basic characteristics, and is in line with the concept of sustainable development. It is a fundamental change with the traditional growth model which is for "mass production, mass consumption, and mass waste." Certainly, circular development complies with the objective law of material circulation in nature and can play a significant optimization effect on the current economic and social development model. In fact, there is still a great potential for resource conservation, utilization and recycling in China's economic operation. Problems in the field of producer responsibility extension of household garbage classification for renewable resources recovery have not been broken through yet, and the market size of renewable products still needs to be further expanded. All these problems need to be solved by relying on high-quality economic development.

Circular development mainly considers problems from the perspective of resource utilization, which should be in line with the principle of 3R, namely, Reduce Reuse and Recycle, so as to use less resources and improve the utilization efficiency of resources as far as possible under the premise of ensuring the needs. Consequently, this paper selects six secondary indicators, including total energy consumption, total water consumption, energy consumption per unit of GDP, water consumption per unit of GDP, daily urban sewage treatment capacity, and comprehensive utilization rate of industrial solid waste under the circular development dimension.

\subsubsection{Green Development}

Green development is a way of economic growth and social development that aims at efficiency, harmony and sustainability. In today's world, green development has become an important trend. Without green development, ecology and nature will be destroyed. Green development focuses on solving the problem of harmony between people and the environment in highquality development, and it is also a new growth point for the world economy. Therefore, to achieve high- quality economic development in the new era, it is necessary to pay more attention to environmental benefits while taking into account economic and social efficiency. And high-quality development should be reflected in the reduction of environmental load and achieve sustainable economic development.

Green development should give more consideration to ecological protection and pollution emission. It should reduce the emission of pollutants as much as possible and increase the area of green space as much as possible in the process of economic development. Eventually, this study selected total sulfur dioxide emissions, total smoke (dust) emissions, total wastewater emissions, chemical oxygen demand emissions, sulfur dioxide emissions per unit of GDP, and smoke (dust) emissions per unit of GDP in the dimension of green development. There are 10 secondary indicators such as total wastewater discharge per unit GDP, chemical oxygen demand discharge per unit GDP, urban green area and urban park green area per capita.

\subsubsection{Low-carbon Development}

Low-carbon development is a sustainable development model characterized by low energy consumption, low pollution and low emissions. It emphasizes the promotion of economic and social development with low carbon emission level, which is of great significance to the sustainable development of economy and society. Climate change concerns the survival and development of all mankind. Promoting low-carbon development is China's major contribution to the earth's environment and an important requirement for high-quality economic development.

Low-carbon development is mainly related to energy utilization. Since the greenhouse effect is mainly caused by carbon dioxide emissions which the main original source is fossil energy, we should try to reduce the use of fossil energy and vigorously increase the use of nonfossil energy. Hence, four secondary indicators are selected including non-fossil energy utilization, nonfossil energy utilization ratio, carbon dioxide emissions per unit of GDP per capita carbon dioxide emission and non-fossil energy utilization ratio in the low-carbon development dimension.

To sum up, the evaluation index system for highquality development from the perspective of ecological civilization constructed in this study can be divided into 3 first-level indicators and 21 second-level indicators (Table 1).

Additionally, the data characteristics of the above indicators are different. Some have large-scale characteristics and some have small-scale characteristics. We regard the former as a positive indicator and the latter as a negative indicator. 


\section{EVALUATION OF CHINA'S HIGH- QUALITY DEVELOPMENT FROM THE PERSPECTIVE OF ECOLOGICAL CIVILIZATION}

\subsection{Evaluation Method}

Additionally, the data characteristics of the above indicators are different. Some have large-scale characteristics and some have small-scale characteristics. We regard the former as a positive indicator and the latter as a negative indicator.

The choice of evaluation method is related to the reliability and accuracy of evaluation results. There are many methods used by scholars in the evaluation of economic development. Among them, subjective weighting method and objective weighting method are mainly used to determine the weight of indicators. Since subjective weighting method can make the weight given by human beings lack objective scientific basis, thus affecting the reliability of evaluation results, so the objective weighting method is often used. Entropy weight method is widely used in objective weighting method.

Entropy weight method (ENTROPY value method) is an objective weighting method, which is widely used in the comprehensive evaluation of multiple indexes. It uses the information entropy value of the index to judge the effectiveness and value of the index, and the weight value of the index given by will not be affected by human factors, which has higher credibility than Delphi method and AHP. Therefore, this paper USES entropy weight method to give weight to the index system, so as to make a comprehensive evaluation of the development level of China's ecological civilization.

Entropy weight method Procedures:

(1) First, the standardization of data. In order to eliminate the dimensional influence of each evaluation index, the normalized treatment of each index data should be carried out, and the processing formula of the forward index should be adopted:

$$
x_{i j}^{\prime}=\frac{x_{i j}-\min \left(x_{i}\right)}{\max \left(x_{j}\right)-\min \left(x_{j}\right)}
$$

The processing formula for negative indicators:

$$
\boldsymbol{x}^{\prime}{ }_{i j}=\frac{\max \left(\boldsymbol{x}_{j}\right)-\boldsymbol{x}_{i j}}{\max \left(\boldsymbol{x}_{j}\right)-\min \left(\boldsymbol{x}_{j}\right)}
$$

(2) Second, Calculate the information entropy of each index:

$$
\begin{aligned}
e_{j} & =-\ln (n)^{-1} \sum_{i=1}^{n} p_{i j} \ln p_{i j}\left(p_{i j}=\frac{x_{i j}^{\prime}}{\sum_{1}^{n} x_{i j}^{\prime}}\right) \\
\text { If } p_{i j} & =0
\end{aligned}
$$

Recommendations: $\lim _{p_{11}-0} p_{i j} \ln p_{i j}=0$
(3) Third, determine the weight of each indicator

$$
\boldsymbol{w}_{j}=\frac{e_{j}}{\sum_{1}^{n} \boldsymbol{e}_{j}}
$$

(4) Last, calculate the development index

$$
v_{i}=\sum_{j=1}^{n} w_{j} p_{i j}
$$

\subsection{Evaluation Result}

\subsubsection{Evaluation Results of Individual Development Index}

Figure 1 is the result of the above method.

First of all, let's start with the circular development index. In the whole period, the circular development index decreased by $9.0 \%$ from 0.0156 to 0.0142 , with an average annual decrease of $0.5 \%$. This shows that there is little progress in China's circular development, which may be closely related to the rapid growth of resource consumption and the slow increase of recycling utilization rate of resources due to China's economic development. However, From a modest point of view, there is still a good progress in phases. The average annual change rate of the circular development index has dropped from $3.5 \%$ during the "Tenth Five-Year Plan" period, and after a decline of $0.2 \%$ during the "Eleventh Five-Year Plan" period, it has developed to the period 2010-2017. The increase of $1.4 \%$ is a gradual change in the positive direction.

Then, in the whole period from 2000 to 2017 , China's green development index has increased, from 0.0143 to 0.0387 , an increase of 1.7 times, with an average annual increase of $6.0 \%$, which is the largest increase among the three single indexes, but the development is also very uneven. In terms of phrases, the average annual decrease during the 10th Five Year Plan period was $1.4 \%$, the average annual increase during the 11th Five Year Plan period was $13.6 \%$, and the average annual increase was $6.4 \%$ from 2000 to 2017.

Last, let's look at the low carbon development index. From 2000 to 2017, the low-carbon development index increased slightly, from 0.0278 to 0.0316 , with an average annual increase of $0.7 \%$, but the development was more unbalanced. During the 10th Five Year Plan period, the average annual decrease was $10.7 \%$, and during the 11th Five Year Plan period, it increased by $1.8 \%$, while from 2010 to 2017 , it increased by $9.1 \%$, which also affected the ecological civilization comprehensive index. Look at the low-carbon development index. From 2000 to 2017, the low-carbon development index rose slightly, from 0.0278 to 0.0316 , an average annual increase of $0.7 \%$, but the development was even more uneven, with an average 
annual decline of $10.7 \%$ during the "Tenth Five-Year Plan" period. There has been a rebound, with an average annual increase of $1.8 \%$, and a sharp increase of $9.1 \%$ per year from 2010 to 2017, which also affects the comprehensive index of ecological civilization and the fastest increase in this period.

In short, since the beginning of the 21 st century, China's ecological civilization has improved. Overall, among the three individual development indexes, the green development index has the highest average annual growth rate, the low-carbon development index is in the middle, and the circular development index is the lowest. The importance of environmental quality improvement is relatively high, but insufficient attention is paid to the urgency of resource conservation and recycling and low-carbon development.

If it is divided into three stages, it generally shows a trend of gradual improvement with the passage of time. During the "Tenth Five-Year Plan" period, the three individual development indexes all declined; during the "Eleventh Five-Year Plan" period, they gradually turned to rise, but the development was very uneven. The green development index grew the fastest, at over $10 \%$, while the circular development index hardly increased. ; After 2012, the development tends to be balanced and all are positive growth.

This trend is even more pronounced when the entire period is divided into two phases, with the year 2010 as the boundary. The average annual growth rate of the previous stage, the Green Development Index, was $5.8 \%$, while the Circular Development Index and Low Carbon Development Index decreased by $1.9 \%$ and $4.7 \%$. The annual growth rate of the Development Index in the latter stage was $6.4 \%, 1.4 \%$ and $9.1 \%$. The growth rate of the three individual indexes is better in the later period than in the early period.

\subsubsection{Comprehensive Development Index Evaluation Results}

It can be seen from Figure 1 that from 2000 to 2017, China's ecological civilization development index rose from 0.0577 to 0.0845 , with an average annual growth of $2.3 \%$, indicating that China has made certain progress in ecological civilization construction. However, from the perspective of development process, the period is not stable and has great fluctuations, which can be roughly divided into three different stages.

Wandering and descending period: During the tenth Five-year Plan period from 2000 to 2015, the growth rate in 2001 and 2002 was followed by a continuous downward trend. In 2005, compared with 2000, the development index declined instead of rising, with an average annual decline of $6.1 \%$.
Unbalanced development period: During the 11th Five-Year Plan period from 2005 to 2010, except for the decline in 2006, the development index increased continuously with an average annual increase of $5.6 \%$. However, as mentioned above, the development of the three individual indexes is very unbalanced.

Stable rising period: In the seven years after 2010, except for the decline in 2011, the subsequent years have steadily increased. The development index has risen by $53 \%$ during the seven-year period, with an average annual growth rate of $6.4 \%$.

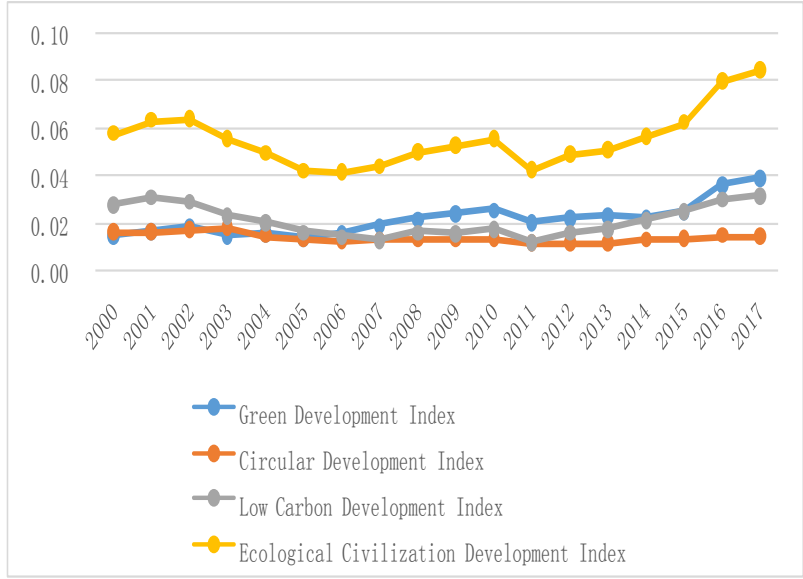

Figure 1. China's High quality development Index from the Perspective of Ecological Civilization (2000-2017)

Source: Written by the author

\section{CONCLUSIONS AND RECOMMENDATIONS}

Based on the perspective of ecological civilization, this paper selects 21 observation indexes and constructs the evaluation index system of China's high-quality development from the three dimensions of green development, circular development and low-carbon development, and uses entropy weight method to evaluate the development status of China from 2000 to 2017. The results of the study are shown below.

\subsection{Overview as a Whole}

China's high-quality development of ecological civilization has made some progress on the whole, and the development trend is good, but the development is not balanced, the green development speed is fast, while the low-carbon development and circular development speed is slow, especially the circular development almost has no progress.

\subsection{Analysis per Periods}

In terms of stages, the period from 2000 to 2005 was in a declining and wandering period, during which circular development and green development and low- 
carbon development showed negative growth, and of course, the comprehensive development index tended to decline. In 2010, the "Eleventh Five-Year Plan" period was in a period of unbalanced development. During this period, circular development declined slightly, lowcarbon development increased slightly, and green development increased substantially, making the comprehensive development index showing a slow growth trend; After 2010-2017, it is in a period of steady increase (except 2010-2011). The circular development index has changed from a decline to an increase. Although the green development index is not as good as the "Eleventh Five-Year Plan" period, it has maintained a relatively high growth rate. The carbon development index has increased substantially which lead to a rapid increase in the comprehensive development index.

Based on the above analysis, the author believes that from the perspective of ecological civilization construction, China's high-quality development has made certain achievements, but the level of development is not high enough, there is still room for improvement. In view of the development of China's ecological civilization in time is not stable, also not enough balance in the various indicators. In the process of vigorously promote the construction of ecological civilization in the future, we should pay attention to the balanced development of ecological civilization, in addition to continue to strengthen the environmental quality improvement, we should increase the intensity of resource efficient using of energy transformation, in this way, the ecological civilization construction of high quality development in our country meets the demand of The Times.

\section{REFERENCES}

[1] Zhu Weidong, Zhou Fei, Wei Boning. Construction and Measurement of China's High-quality development Index System in the New Era[J], Wuhan Finance, 2019 (12): pp.18-26

[2] Zhu Qigui, Establishing an Indicator System to Promote High-quality Development [N], Wen Hui Po, 2018-02-06 (12)

[3] Song Mingshun, Zhang Xia, Yi Ronghua, Zhu Tingting, A study on the evaluation system of the quality of economic development and its
applications[J], Economist 2015 (2): pp.35-43. DOI: 10.16158/j.cnki.51-1312/f.2015.02.004

[4] Wei Min, Li Shuhao. The Construction and Measurement of the Evaluation System of China's Economic Growth Quality under the New Normal [J], Economist, 2018(4): 19-26. DOI: 10.16158/j.cnki.51-1312/f.2018.04.004

[5] Lu Jitong. A Preliminary Study of China's Highquality Development Index System [J], China Economic and Trade Guide, 2017 (7): pp.4-7.

[6] Xu Yongbing, Luo Peng, Zhang Yue. Construction and Measurement of High quality development Indication System: Taking Hebei Province as an Example [J], Journal of Hebei University (Philosophy and Social Science), 2019, 44(3): pp.86-97. DOI: 10.3969/j.issn.10056378.2019.03.013

[7] Han Junhui, Shakhzod Shokirov, Liu Yang. Research on the Comprehensive Evaluation of High quality Development Based on Entropy Method[J], Science Technology and Industry, 2019, 19(6): pp.79-83

[8] Liu Gan, Zheng Siyu. Comprehensive Evaluation of China's Regional Economic High quality Development[J], Productivity Research, 2018 (10): pp.59-63.DOI:10.19374/j.cnki.141145/f.2018.10.012

[9] Song Xiaona, Zhang Feng. Industrial Development Quality Measurement and Trend Research under High-quality Development [J], Soft Science, 2019, 33(12): pp.36-41. DOI: 10.13956/j.ss.10018409.2019.12.06

[10]Liang Tao. Thoughts on the Establishment of a High-quality Development Index System for China's Manufacturing Industry [J], Economic Outlook the Bohai Sea, 2019 (4): pp.67-68. DOI: 10.16457/j.cnki.hbhjjlw.2019.04.045

[11]Zhang Wenhui, Qiao Baohua. S Thoughts on Constructing the High-quality Development Index System of Manufacturing Industry [J], Industrial Economy Review, 2018 (4): pp.27-32 